\title{
Moderate hypothermia prevents neural cell apoptosis following spinal cord ischemia in rabbits
}

\author{
Lei Ming WANG ${ }^{1,3,}$, Ye YAN ${ }^{2, *}$, Liang Jian $\mathrm{ZOU}^{1}$, Nai He JING ${ }^{2, * *}$, Zhi Yun $\mathrm{XU}^{1, * *}$ \\ ${ }^{1}$ Department of Cardiovascular Surgery, Changhai Hospital, Shanghai 200433, China \\ ${ }^{2}$ Laboratory of Molecular Cell Biology, Laboratory of Stem Cell Biology, Institute of Biochemistry and Cell Biology, Shang- \\ hai Institutes for Biological Sciences, Chinese Academy of Sciences, Shanghai 200031, China \\ ${ }^{3}$ Department of Cardiovascular Surgery, The 85th Hospital, Shanghai 200052, China
}

\begin{abstract}
Paraplegia is a disastrous complication after operations of descending and thoracoabdominal aortic aneurysm. Regional hypothermia protects against spinal cord ischemia although the protective mechanism is not well know. The objective of this study is to examine whether hypothermia protects the spinal cord by preventing apoptosis of nerve cell and also investigate a possible mechanism involved in hypothermia neuroprotection. Cell apoptosis with necrosis was evident in the spinal cord $24 \mathrm{~h}$ after $30 \mathrm{~min}$ of ischemia. Moderate hypothermia decreased the incidence of apoptotic nerve cells. Both cell apoptosis and necrosis were attenuated by hypothermia. p53 expression increased and bcl-2 expression declined after ischemia, while hypothermia mitigated these changes. This study suggests that apoptosis contributes to cell death after spinal cord ischemia, and that moderate hypothermia can prevent nerve cell apoptosis by a mechanism associated with bcl-2 and p53 genes.
\end{abstract}

Keywords: spinal cord, ischemia, apoptosis, hypothermia.

\section{INTRODUCTION}

Spinal cord ischemic injury remains a devastating complication after operations of descending and thoracoabdominal aortic aneurysm. In spite of advances in surgical techniques and protective adjuncts, the incidence of paraplegia or paraparesis still ranges from 5-10\% [1]. Moreover, some patients who undergo thoracic aneurysm repair and awaken with no neurological dysfunction immediately after the operation sometimes develop delayed-onset paraplegia 1 to $5 \mathrm{~d}$ later [2]. The cause of delayed onset has been attributed to postoperative hypotension, embolization or thrombosis to anterior spinal artery, and occlusion of reimplanted intercostal arteries. Recent studies suggest neuronal apoptosis occurs concurrently with ne-

\footnotetext{
*These authors contributed equally to this work.

**Correspondence: Nai He JING ${ }^{1}$, Zhi Yun XU ${ }^{2}$

${ }^{1}$ Tel: +86-21-5492-1381; Fax: +86-21-5492-1011;

E-mail: njing@sibs.ac.cn

${ }^{2}$ Tel: +86-21-2507-2914; Fax: +86-21-6549-0979;

E-mail: zhiyunxu@smmu.edu.cn
}

crosis following spinal cord ischemia and may contribute to delayed onset of neuronal cell death [3]. It has been suggested that spinal motoneurons are more vulnerable to ischemia. Delayed and selective death of motoneurons after transient ischemia may not be necrotic but rather predominantly apoptotic which is accompanied with cytochrome $c$ release and induction of caspases, cyclin D1 and cdk4 protein [4-7]. Hypothermia has been proved as an efficient method for spinal cord protection following ischemia [8]. Early studies showed hypothermia could reduce tissue metabolism, restrain the synthesis and release of excited neurotransmitter, and inhibit the inflammation caused by ischemia $[9,10]$. Recent work suggested that mild or moderate hypothermia mitigates neuronal apoptosis induced by hypoxia or ischemia in cultured brain tissues or brain in vivo $[11,12]$. However, little is known about the effect of hypothermia on neuronal apoptosis in spinal cord. The objective of this study is to investigate whether hypothermia prevents neural cell apoptosis after spinal cord ischemia in a rabbit model, and furthermore, if the protective effects of hypothermia are related to alterations of p53 and bcl-2 expression. 


\section{MATERIALS AND METHODS Animal models}

Animals were treated according to the guidelines for the care and use of laboratory animals in all experiments (NIH Publication No. 86-23, revised 1985). The rabbit model of spinal cord ischemia and epidural cooling was established according to Martelli et al. [9]. Twenty-four New Zealand white rabbits weighing between 2.5 and $3.0 \mathrm{~kg}$ were used in this study. The rabbits were divided into 3 groups: a sham control group (group $\mathrm{S}, \mathrm{n}=8$ ), a 30 -min ischemia group (group I, $\mathrm{n}=8$ ) and a 30-min ischemia with epidural cooling group (group $\mathrm{H}, \mathrm{n}=8$ ). Animals underwent anesthesia with an intramuscular cocktail of ketamine hydrochloride $(60 \mathrm{mg} / \mathrm{kg})$ and Diazepam $(4 \mathrm{mg} / \mathrm{kg})$. Spinal cord ischemia was induced by infrarenal aortic occlusion for $30 \mathrm{~min}$. For group $\mathrm{H}$, the spinal cord was cooled with an extracorporeal perfusion system consisted of a roller pump and a glass coil immersed in a water bath. The temperature of the spinal cord was lowered to $(26-28)^{\circ} \mathrm{C}$. Each group of animals was divided into three experimental subgroups: group A for hematoxylin and eosin staining (H\&E), Hoechst and TUNEL staining $(n=3)$, group B for electron microscopy $(\mathrm{n}=2)$, and group $\mathrm{C}$ for DNA fragmentation and RT-PCR analysis $(n=3)$. The motor function was assessed at $24 \mathrm{~h}$ with the modified Tarlov's criteria [13]. A score of 0-4 was assigned to each animal as follows: 0 , no voluntary movement; 1 , perceptible movement of joints, active movement but unable to stand; 3 , able to stand but unable to walk; and 4, complete recovery of hindlimb function. Statistical comparisons were analyzed by KruskalWallis test, and a value of $P<0.05$ was considered as significant and $P<0.01$ as extremely significant.

\section{Histological study}

Rabbits were anesthetized $24 \mathrm{~h}$ after experimental or sham procedures and exsanguinated through the right atrium $(n=3)$. The spinal cord was perfused with saline solution ( $1 \%$ heparin) quickly, followed by $4 \%$ paraformaldehyde in $0.1 \mathrm{M}$ phosphate buffered saline (PBS, $\mathrm{pH}$ 7.6). The lumbar segments of the spinal cord were harvested and fixed in $10 \%$ formalin in PBS for $12 \mathrm{~h}$, and then embedded in paraffin and transverse sections were cut with a thickness of 6-8 ìm at L5 level. Some sections were stained with $H \& E$, and examined by light microscopy. Several sections were stained with Hoechst $33258(5 \mu \mathrm{g} / \mathrm{ml})$ for $7 \mathrm{~min}$, and visualized by fluorescence microscopy.

\section{Electron microscopy}

Rabbits were anesthetized $24 \mathrm{~h}$ after experimental or sham procedures and perfused with $4 \%$ paraformaldehyde and $1.25 \%$ glutaraldehyde in PBS, then the spinal cord was removed at L5 level $(\mathrm{n}=2)$. Slabs were immersion-fixed overnight in $2.5 \%$ glutaraldehyde in PBS at $4^{\circ} \mathrm{C}$. Ultrathin sections ( 60 to $90 \mathrm{~nm}$ ) were prepared according to Mackey et al. [3] and examined on a ZEISS-EM902 transmission electron microscope.

\section{TUNELstaining}

TUNEL was performed on paraffin sections using an in situ cell death detection kit (Roche). Tissue sections were deparaffinized and rehydrated, then labeled by dUTP-fluorescein according to the manufacturer's instructions. Some sections were also stained with Hoechst 33258, and then visualized by fluorescence microscopy. We counted TUNEL positive cells and total cells (Hoechst staining) in the ventral gray matter in 4 sections/animal at a magnification of $\times 200$ for quantitative measurement of the percentage of neural cells that underwent apoptosis. The ratio was expressed as the mean \pm SD. Statistical comparisons were analyzed by ANOVA, and a value of $P<0.05$ was considered as significant and $P<0.01$ as extremely significant.

\section{Analysis of DNA fragmentation}

Spinal cord at L5 level was quickly removed and frozen in liquid nitrogen. Total genomic DNA was prepared according to the method of Sambrook et al. [14] and subjected to $1.8 \%$ agarose gel electrophoresis and visualized with ethidium bromide $(0.5 \mu \mathrm{g} / \mathrm{ml})$. Lowmolecular weight DNA was prepared according to the method of Linnik et al. [15], separated on a 5\% nondenaturing polyacrylamide gel, and visualized by silver staining.

\section{RT-PCR analysis}

Total RNA was isolated from L5 spinal cord using TRIzol reagent (Invitrogen). $2 \mu \mathrm{g}$ RNA were added in $20 \mu \mathrm{L}$ of reaction mixture and preheated for $10 \mathrm{~min}$ at $80^{\circ} \mathrm{C}$ with 100 pmol Random Primer (Invitrogen). The first-strand cDNA was synthesized by SuperScript II reverse transcriptase (Invitrogen) at $42^{\circ} \mathrm{C}$ for $1 \mathrm{~h}$. The reaction was terminated at $70^{\circ} \mathrm{C}$ for $15 \mathrm{~min} .1 \mu \mathrm{L}$ of the cDNA mixture was used for subsequent PCR $(10 \mu \mathrm{L})$ with the following primer set: bcl-2 forward, 5'-GTGGCCTTCTTTGAGTTCG-3'; bcl-2 reverse, 5'CTTCAGAGACAGCCAGGAG-3' (product size 212bp) [16] p53 forward, 5'-ACCTTCCGACACAGCGTGGT-3'; p53 reverse, 5'CTCCATCCAGCGGCTTCTTC-3' (349bp) [17] glyceraldehyde3-phosphate dehydrogenase (GAPDH) forward, 5'-ACCACGGTG CACGCCATCAC-3', GAPDH reverse, 5'-TCCACCACCCTGTT GCTGTA-3' (454bp). PCR were conducted with an initial denaturation at $94^{\circ} \mathrm{C}$ for 5 min followed by 35 cycles (bcl-2 and p53) and 25 cycles (GAPDH) of amplification. Each cycle consists of $30 \mathrm{sec}$ of denaturation at $94^{\circ} \mathrm{C}, 30 \mathrm{sec}$ of annealing at $55^{\circ} \mathrm{C} \mathrm{(bcl-2,} \mathrm{GAPDH)} \mathrm{or}$ $57^{\circ} \mathrm{C}(\mathrm{p} 53)$, and $1 \mathrm{~min}$ of extension at $72^{\circ} \mathrm{C}$. The last cycle was followed by a final extension for $7 \mathrm{~min}$ at $72^{\circ} \mathrm{C}$. GAPDH was used as a reference control. Our initial experiments determined that cDNA amplification was linear within 30 to 40 cycles of PCR for bcl-2 and p53 (data not shown). PCR products were analyzed by agarose gel electrophoresis. All experiments are repeated four times.

\section{RESULTS}

Rabbits in sham group recovered without neurologic deficit at $24 \mathrm{~h}$, while all the rabbits with aortic occlusion in group I had paraplegia or paraparesis. In group $\mathrm{H}$, all rabbits were neurologic intact except one. The numbers of animals with paraplegia were significantly less in the hypothermia treatment group $(P<0.01)$.

\section{Histological study}

Representative photographs of HE-stained sections are shown in Fig. 1. The spinal cord was intact in sham-operated animals with many large motoneurons in the anterior horn (Fig. 1A), and no change was observed in neural cells including neurons and glial cells. However, many motoneurons as well as glial cells disappeared in the spinal cords from rabbits subjected to $30 \mathrm{~min}$ ischemia, and necrotic changes and neurophil vacuolation of the gray mat- 


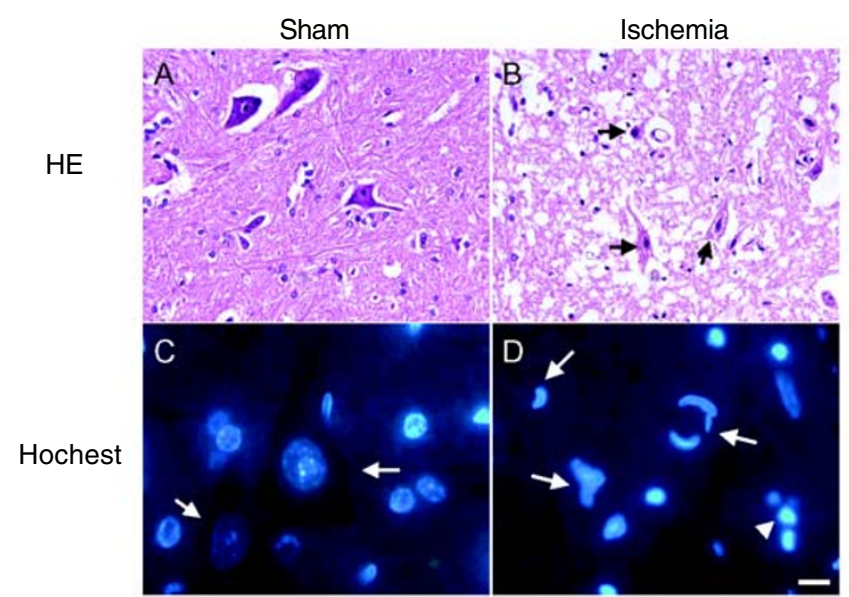

Fig. 1 Cross paraffin sections $(6-8 \mu \mathrm{m})$ of spinal cord at L5 level stained with H\&E (A, B) and Hoechst 33258 (C, D). Spinal cord of sham group showed no histological changes (A). Motoneurons were partly lost and some neurons exhibited apoptotic characteristics $24 \mathrm{~h}$ after ischemia, (B, arrows). By Hoechst staining, sections of sham control showed normal nuclear form (C, arrows), while after ischemia, the nuclei exhibited typical apoptotic morphology as condensed and fragmented (D, arrows). The apoptotic bodies could also be detected (D, arrowheads). A, B, bar $=30 \mu \mathrm{m} ; \mathbf{C}, \mathbf{D}$, bar $=10 \mu \mathrm{m}$.

ter became evident (Fig. 1B). In addition, some neurons exhibited apoptotic characteristics such as cell shrinkage, chromatin condensation and nuclear budding (Fig. 1B, arrows). Nuclear staining by Hoechst 33258 showed that the nuclei of motoneurons appeared normal (Fig. 1C, arrow) in sham group, while apoptotic nuclei with condensed chromatin and nuclear fragments were evident in ischemia group (Fig. 1D, arrows) [18]. Apoptotic bodies were verified (Fig. 1D, arrowheads).

\section{Electron microscopy}

Electron microscopy illustrated an ultrastructure of apoptosis in damaged neurons. Nuclear chromatin in sham group was evenly distributed (Fig. 2A), while cells with different stages of apoptotic features were distinguishably identified in the ischemic group (Fig. 2B-D). In contrast to the early apoptotic changes that included dense aggregation of chromatin around the margin of the nucleus with intact nuclear membranes (Fig. 2B, arrows), advance apoptotic changes included nuclear fragmentation with condensed cytoplasm and intact cytoplasmic organelles as mitochondria (Fig. 2C, arrow). In the late stages of apoptosis, condensed chromatin masses bud into membrane-bounded apoptotic bodies (Fig. 2D, arrow). The results in Fig. 1 and Fig. 2 indicate that neural cell apoptosis occurred in the spinal cord at $24 \mathrm{~h}$ following $30 \mathrm{~min}$ ischemia.

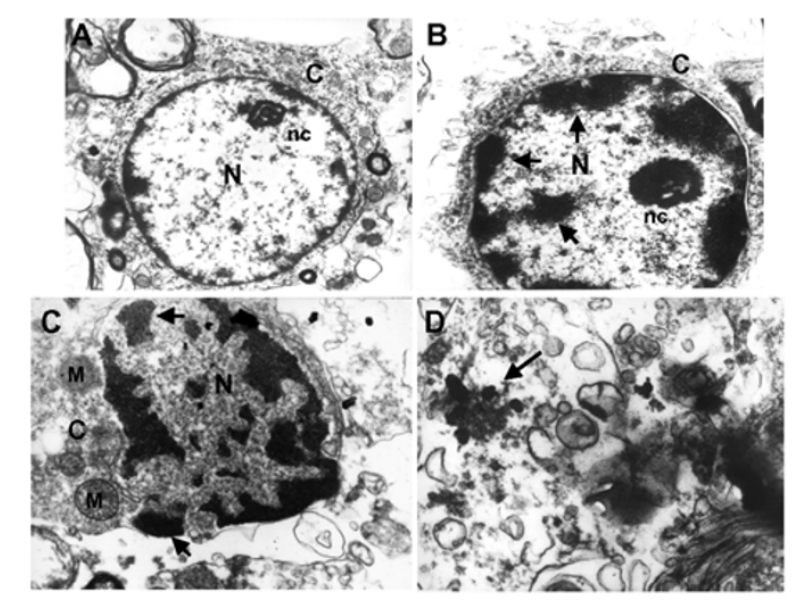

Fig. 2 Ultrastructural appearance of neurons in lumbar spinal cord (A, Sham-operation; B-D, 24h after $30 \mathrm{~min}$ ischemia) by electron microscope. Early apoptotic changes included dense aggregation of chromatin (B, arrows) with preservation of nuclear membranes. Advance apoptotic changes included nuclear fragmentation ( $\mathbf{C}$, arrows) and intact mitochondria. Formation of apoptotic bodies containing condensed chromatin fragments and packed cytoplasmic organelles was detected in late-stage apoptosis (D, arrow). N, nucleus; nc, nucleolus; C, cytoplasm; M, mitochondria. Original magnification: (A) $\times 11200$; (B) $\times 19200$; (C) $\times 19200$; (D) $\times 32000$.

\section{TUNEL staining}

Our investigation was then focused on the possibility that moderate hypothermia prevents neural cell apoptosis in our model. HE staining of tissue from the hypothermia protected group $(\mathrm{H})$ showed relatively normal histological morphology as compared to tissue from normothermic ischemia group (I) (Fig. 3A-C). There was less evidence of apoptotic motoneurons and glial cells found in group $\mathrm{H}$. Cells that displayed morphological features of apoptosis could be labeled by TUNEL staining in which double-strand breaks in DNA were labeled with dUTP-fluorescein (Fig. $3 \mathrm{G}, \mathrm{H}, \mathrm{I})$. The nuclei of all cells in the same field were also revealed by Hoechst staining (Fig. 3D, E, F). Few cells were weakly stained by TUNEL reaction in the anterior horn of sham-operated animals (Fig. 3G), whereas many cells were intensely stained in the anterior horn in sections of spinal cord after ischemia (group I) (Fig. 3H). However, moderate hypothermia protection decreased staining and reduced the number of TUNEL-positive cells (Fig. 3I). Quantitative analysis (Fig. 3J) indicated that the percentage of TUNEL-positive cells in anterior horn was increased significantly in ischemia group $(P<0.01)$, while reduced by hypothermia protection $(P<0.01)$. This suggests that moderate hypothermia can reduce neural cell apoptosis caused by ischemia injury. 

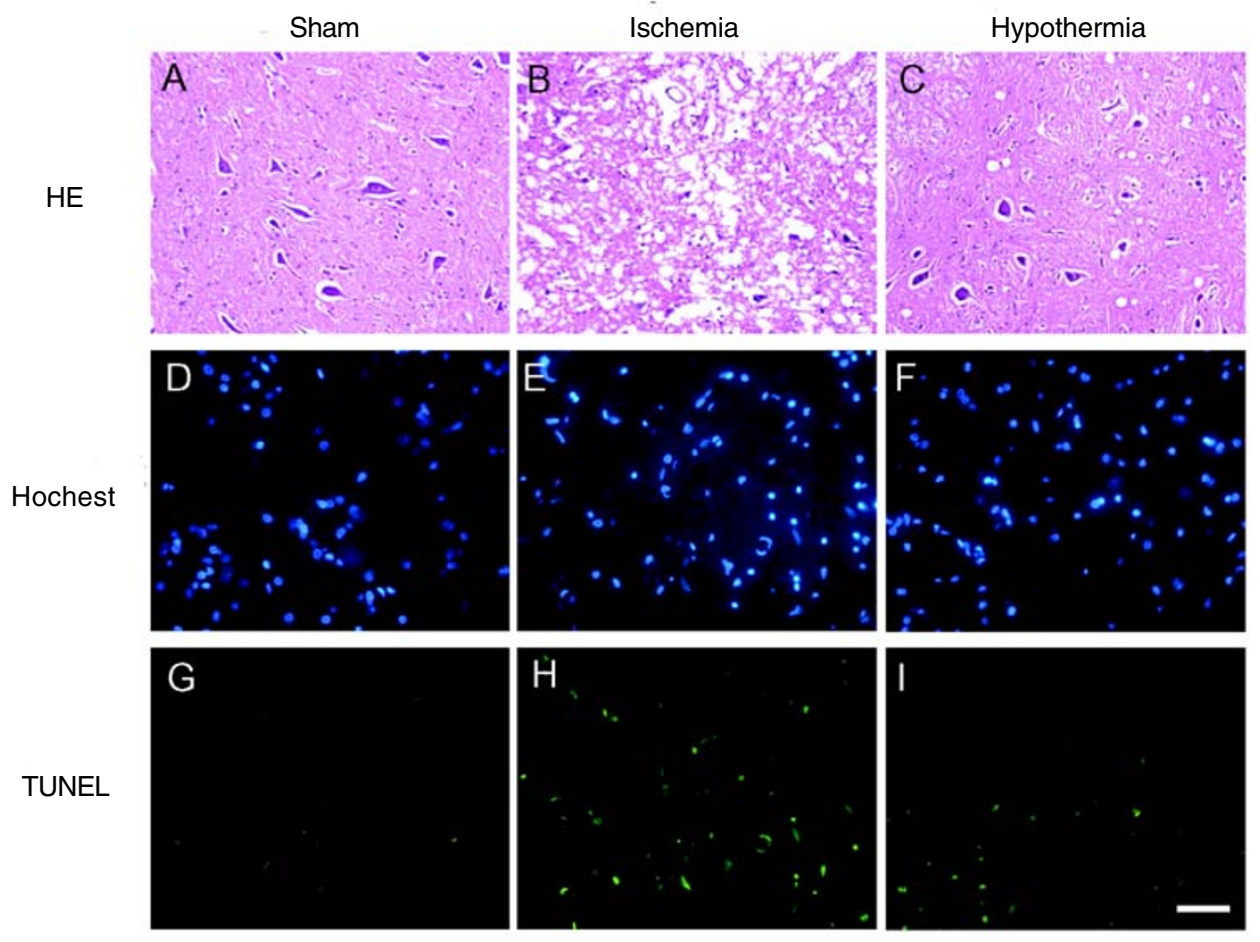

$\mathrm{J}$

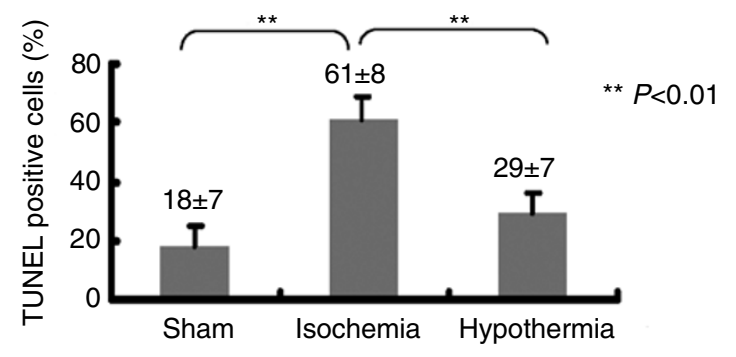

\section{Analysis of DNA fragmentation}

Nucleosomal fragmentation by endonuclease cleavage is a well-defined biochemical marker of cells undergoing apoptosis which results in DNA fragments with multiples of $180 \mathrm{bp}$, as compared to necrosis that causes nonspecific degradation of DNA into random-sized fragments [19]. Gel electrophoresis of the total genomic DNA from L5 spinal cord of three groups was presented in Fig. 5A. DNA from the sham-operated spinal cord was largely intact and exhibited little migration in the gel. DNA from the ischemia group exhibited a characteristic nucleosome ladder which might result from DNA endonucleolytic digestion (Fig. 4A lane I, arrows). A smear pattern resulting from random DNA degradation suggests that necrosis might have occurred concurrently with apoptosis. Degradation of DNA from the hypothermia group was reduced
Fig. 3 Hypothermia prevents cell apoptosis after spinal cord ischemia. Histological photomicrographs by H\&E staining in sham group (A), ischemia group (B) and hypothermia group (C) showed hypothermia prevents ventral gray matter from pathological changes. TUNEL staining (green) and the corresponding Hoechst staining (blue) of the sham group $(\mathbf{D}, \mathbf{G})$, ischemia group $(\mathbf{E}, \mathbf{H})$ and hypothermia group $(\mathbf{F}, \mathbf{I})$ were shown and the ratios of TUNEL-positive cells in anterior horn of the three groups were indicated in $(\mathbf{J})$. Many TUNEL-stained cells were detected in anterior horn after ischemia, while with hypothermia protection, apoptotic cells were remarkably decreased $(P<0$. 01). A, B, C, bar= $100 \mu \mathrm{m} ; \mathbf{D}, \mathbf{E}, \mathbf{F}, \mathbf{G}, \mathbf{H}, \mathbf{I}$, bar $=50 \mu \mathrm{m}$.

and a faint ladder became evident (Fig. 4A, lane $\mathrm{H}$, arrows). To further distinguish the DNA ladder, low-molecular weight DNA was prepared for gel electrophoresis (Fig. 4B). DNA from the sham group showed little detectable degradation. A DNA ladder with a smear pattern appeared in the DNA after spinal cord ischemia; whereas DNA degradation was reduced and a faint ladder was observed with hypothermia protection (Fig. 4B, arrows). Results from DNA fragmentation analysis demonstrate that hypothermia largely decreased cell apoptosis and necrosis after spinal cord ischemia.

\section{RT-PCR analysis}

It has been indicated that $\mathrm{p} 53$ tumor suppressor protein is essential for neuronal apoptosis in response to a variety of insults, including DNA damage, ischemia and 
A

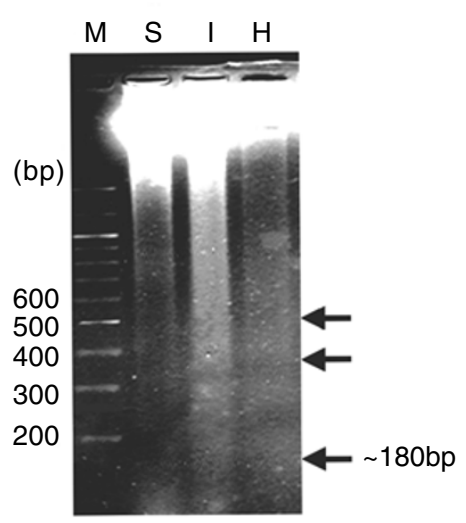

B

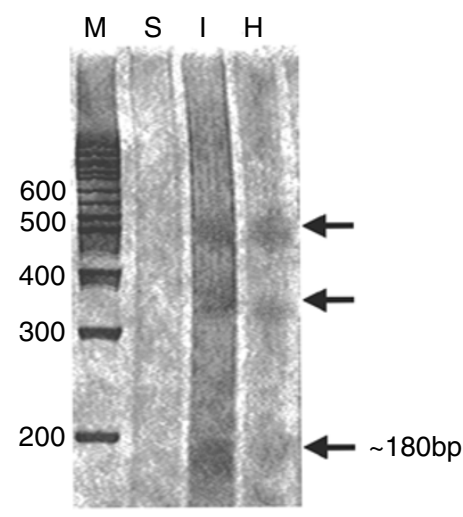

Fig. 4 Gel electrophoresis of the genomic DNA (A) or low-molecular weight DNA (B) exacted from spinal cord of the sham group (S), ischemia group (I) and hypothermia group $(\mathrm{H})$. Almost no DNA degradation was detected in sham operation. DNA ladder with oligonucleosome fragments appeared with a smear pattern in group $\mathrm{I}$, while a faint ladder was shown in group $\mathrm{H}$. Arrows indicated bands in multiples of $180 \mathrm{bp}$ DNA fragments. M: 100bp ladder.

excitotoxicity, and bcl-2, a member of the bcl-2 family, plays a major role in protection of central nervous system against these insults [20]. The mRNA expression of p53 and bcl-2 gene was examined by RT-PCR amplification of the sham, ischemic and hypothermic groups. PCR products at the expected size were shown in Fig. 5. bcl-2 expression (212 bp band) was clearly observed in the lane of sham group; whereas a faint band was detected in ischemia group, while bcl-2 expression was increased by hypothermia protection. p53 expression (349 bp band) was enhanced in ischemia animals compared with the sham group, whereas p53 mRNA decreased in hypothermia group. GAPDH expression (454 bp band) exhibited no change.

\section{DISCUSSION}

This study demonstrates that hypothermia supports

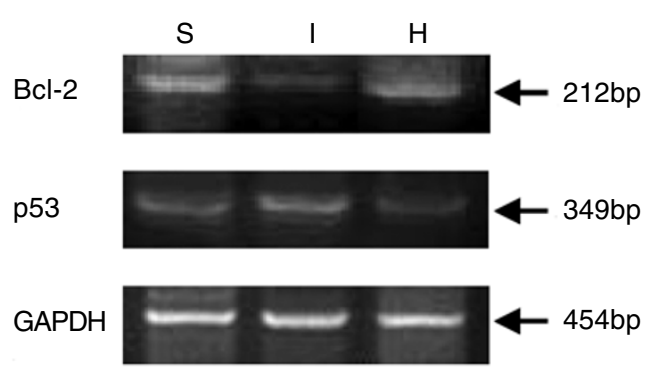

Fig. 5 RT-PCR analysis of bcl-2 (212bp), p53 (349bp) and GAPDH (454bp) mRNA expression. Bcl-2 expression was decreased and p53 expression was enhanced in ischemia group (I) compared with sham group (S), while bcl-2 mRNA increased and p53 mRNA decreased again with hypothermia protection $(\mathrm{H})$. GAPDH was used as loading control. Results are representative of four separate experiments.

optimal protection against spinal cord ischemia and moderate hypothermia can remarkably decrease the number of TUNEL-positive neural cells. The faint ladder within a smear pattern after hypothermia protection indicates that hypothermia may prevent neural cells from apoptosis and necrosis at the same time.

After spinal cord ischemia, accumulated reactive oxygen specie (ROS) caused DNA damage [21], and there was evidence of caspases induction in the motoneurons of rabbit model [5]. In a mouse model, spinal cord ischemia induced cytochrome $c$ release from mitochondria and caspase-3 activation [7]. Such findings suggested that the mitochondrial pathway might be involved in spinal cord ischemia leading to neuronal apoptosis [20].

Hypothermia could inhibit apoptosis by decreasing generation of ROS, cytochrome $c$ release and also increasing bcl-2 expression in some instances in cerebral ischemia [22-24]. On the other hand, hypothermic protection was associated with decreases in caspase 3 and caspase 9 activity and also cytochrome $c$ translocation in an apoptotic model of cultured cortical neurons [25]. This study indicated that hypothermia might be able to attenuate apoptosis through a mitochondrial pathway in cerebral ischemia. However, it remains unknown that how hypothermia protects against cell apoptosis in spinal cord ischemia.

DNA damage leads to $\mathrm{p} 53$ activation, and therefore decreases bcl-2 level in the mitochondrial pathway [20]. We found $\mathrm{p} 53$ expression was increased and bcl-2 expression was decreased after spinal cord ischemia, and meanwhile hypothermia protection mitigated these changes. Our results indicate that the levels of expression of bcl-2 and p53 were associated with spinal cord ischemia and hypothermia protection. While $\mathrm{p} 53$ expression is usually elevated in damaged neurons in acute models of injury such as 
ischemia and epilepsy [26], the absence of p53 had been found to protect neurons from various acute insults. Targeted disruption of bcl-2 gene in mice exacerbates focal ischemic brain injury [27], whereas bcl-2 overexpression protects against cerebral ischemia either by vector-mediated overexpression or in transgenic animal models [28, 29]. Therefore, the fact of decreased $\mathrm{p} 53$ and increased bcl-2 expression in the spinal cord with hypothermia implies an underlying mechanism for the observed neuroprotection.

Hypothermia is the most efficient approach to reduce the rate of paraplegia after operations on the thoracoabdominal aorta. The results of this study suggest that the neuroprotective benefit of hypothermia may be attributed to preventing neural cell apoptosis and also necrosis. Since a combination treatment of hypothermia and bcl-2 overexpression by gene transfer in stroke models can improve their therapeutic benefits [30], clinical studies with combination of hypothermia and gene transfer-mediated upregulation of bcl-2 protein or down-regulation of $\mathrm{p} 53$ protein are recommended for prevention of spinal cord ischemia in the future.

\section{ACKNOWLEDGEMENT}

We would like to thank Sheng Dong HUANG, Yan Ling LIU, Yu Dong ZHANG for their technical assistance. This work was supported in part by National Natural Science Foundation of China (90208011, 30300174, 30470856 and 30421005), National Basic Research Program (973 Program) (2002CB713802), Shanghai Key Project of Basic Science Research (04DZ14005 and 04DZ05608).

Received, Sep 8, 2004

Revised, Mar 14, 2005

Accepted, Apr 1, 2005

\section{REFERENCES}

1 Cambria RP, Clouse WD, Davison JK, et al. Thoracoabdominal aneurysm repair: Results with 337 operations performed over a 15-year interval. Ann Surg 2002; 236:471-9.

2 Moore WM, Jr., Hollier LH. The influence of severity of spinal cord ischemia in the etiology of delayed-onset paraplegia. Ann Surg 1991; 213:427-31.

3 Mackey ME, Wu Y, Hu R, et al. Cell death suggestive of apoptosis after spinal cord ischemia in rabbits. Stroke 1997; 28: 2012-7.

4 Sakurai M, Hayashi T, Abe K, Sadahiro M, Tabayashi K. Delayed and selective motor neuron death after transient spinal cord ischemia: A role of apoptosis? J Thorac Cardiovasc Surg 1998; 115:1310-5.

5 Hayashi T, Sakurai M, Abe K, et al. Apoptosis of motor neurons with induction of caspases in the spinal cord after ischemia. Stroke 1998; 29:1007-12.

6 Sakurai M, Hayashi T, Abe K, et al. Cyclin d1 and cdk4 protein induction in motor neurons after transient spinal cord ischemia in rabbits. Stroke 2000; 31:200-7.

7 Matsushita K, Wu Y, Qiu J, et al. Fas receptor and neuronal cell death after spinal cord ischemia. J Neurosci 2000; 20:6879-87.

8 Cambria RP, Davison JK, Zannetti S, et al. Clinical experience with epidural cooling for spinal cord protection during thoracic and thoracoabdominal aneurysm repair. J Vasc Surg 1997; 25: 234-41.

9 Martelli E, Cho JS, Mozes G, Gloviczki P. Epidural cooling for the prevention of ischemic injury to the spinal cord during aortic occlusion in a rabbit model: Determination of the optimal temperature. J Vasc Surg 2002; 35:547-53.

10 Busto R, Globus MY, Dietrich WD, et al. Effect of mild hypothermia on ischemia-induced release of neurotransmitters and free fatty acids in rat brain. Stroke 1989; 20:904-10.

11 Bossenmeyer-Pourie C, Koziel V, Daval JL. Effects of hypothermia on hypoxia-induced apoptosis in cultured neurons from developing rat forebrain: Comparison with preconditioning. Pediatr Res 2000; 47:385-91.

12 Phanithi PB, Yoshida Y, Santana A, et al. Mild hypothermia mitigates post-ischemic neuronal death following focal cerebral ischemia in rat brain: Immunohistochemical study of fas, caspase3 and tunel. Neuropathology 2000; 20:273-82.

13 Jacobs TP, Kempski O, McKinley D, et al. Blood flow and vascular permeability during motor dysfunction in a rabbit model of spinal cord ischemia. Stroke 1987; 23:367-73

14 Sambrook J, Russell DW. Molecular cloning: A laboratory manual. $3^{\text {rd }}$ edition. Isolation of high-molecular-weight DNA from mammalian cells using Proteinase K and phenol. Cold Spring Harbor Laboratory Press: Cold Spring Harbor, NY 2001:463-71.

15 Linnik MD, Zobrist RH, Hatfield MD. Evidence supporting a role for programmed cell death in focal cerebral ischemia in rats. Stroke 1993; 24:2002-8.

16 Qin XQ, Sun XH, Luo ZQ. Vasoactive intestinal peptide and epidermal growth factor upregulates bcl-2 gene expression in bronchial epithelial cells. Sheng Li Xue Bao 1999; 51:419-24.

17 Ning XH, Chen SH, Xu CS, et al. Hypothermic protection of the ischemic heart via alterations in apoptotic pathways as assessed by gene array analysis. J Appl Physiol 2002; 92:2200-7.

18 Yan Q, Sage EH. Transforming growth factor-betal induces apoptotic cell death in cultured retinal endothelial cells but not pericytes: association with decreased expression of $\mathrm{p} 21 \mathrm{waf1/}$ cip1. J Cell Biochem 1998; 70:70-83.

19 Wyllie A. Cell death: A new classification separating apoptosis from necrosis. In: Bowen ID LR, ed. Cell death in biology and pathology. Chapman and Hall: London, England 1981:9-34.

20 Hengartner MO. The biochemistry of apoptosis. Nature 2000; 407:770-6.

21 Lin R, Roseborough G, Dong Y, Williams GM, Wei C. DNA damage and repair system in spinal cord ischemia. J Vasc Surg 2003; 37:847-58.

22 Maier CM, Ahern K, Cheng ML,et al. Optimal depth and duration of mild hypothermia in a focal model of transient cerebral ischemia: Effects on neurologic outcome, infarct size, apoptosis, and inflammation. Stroke 1998; 29:2171-80.

23 Kil HY, Zhang J, Piantadosi CA. Brain temperature alters hydroxyl radical production during cerebral ischemia/reperfusion in rats. J Cereb Blood Flow Metab 1996; 16:100-6.

24 Zhang Z, Sobel RA, Cheng D, Steinberg GK, Yenari MA. Mild 
hypothermia increases bcl-2 protein expression following global cerebral ischemia. Brain Res Mol Brain Res 2001; 95:75-85.

$25 \mathrm{Xu}$ L, Yenari MA, Steinberg GK, Giffard RG. Mild hypothermia reduces apoptosis of mouse neurons in vitro early in the cascade. J Cereb Blood Flow Metab 2002; 22:21-8.

26 Li Y, Chopp M, Zhang ZG, et al. p53-immunoreactive protein and p53 mRNA expression after transient middle cerebral artery occlusion in rats. Stroke 1994; 25:849-55.

27 Hata R, Gillardon F, Michaelidis TM, Hossmann KA. Targeted disruption of the bcl-2 gene in mice exacerbates focal ischemic brain injury. Metab Brain Dis 1999; 14:117-24.
28 Antonawich FJ, Federoff HJ, Davis JN. Bcl-2 transduction, using a herpes simplex virus amplicon, protects hippocampal neurons from transient global ischemia. Exp Neurol 1999; 156: 130-7.

29 Martinou JC, Dubois-Dauphin M, Staple JK, et al. Overexpression of bcl-2 in transgenic mice protects neurons from naturally occurring cell death and experimental ischemia. Neuron 1994; 13:1017-30.

30 Zhao H, Yenari MA, Sapolsky RM, Steinberg GK. Mild postischemic hypothermia prolongs the time window for gene therapy by inhibiting cytochrome $c$ release. Stroke 2004; 35:572-7. 